\title{
IT skills gap: A survey of IT students' knowledge in 4 key domains
}

\author{
Kevin Slonka, University of Pittsburgh, slonka@pitt.edu \\ Natalya Bromall, Robert Morris University, bromall@rmu.edu \\ Sushma Mishra, Robert Morris University,mishra@rmu.edu \\ Peter Draus, Robert Morris University,draus@rmu.edu
}

\begin{abstract}
Information Technology (IT) skills gap discourse suggests a mismatch between what students are acquiring in terms of knowledge and skills in their education versus what employers believe are useful skills for doing day to day tasks. Students have a preconception of what is more useful for their careers in terms of skills and tend to value those important skills. However, their notion might not be aligned with market realities, which results in less than desirable employment status. This study serves as the first step in this process by analyzing the skills of college students in IT-related majors and offering suggestions that can benefit not only the students but also industry companies and educational institutions. A survey is conducted where IT students rank their level of expertise in multiple domains of IT. Implications are drawn and a conclusion is presented.
\end{abstract}

Keywords: IT skills, survey, Infrastructure, development, emerging technologies, competencies, cyber security

\section{Introduction}

The demand for Information Technology (IT) specialists grows each year, with the expected growth rate from 2019 to 2029 being $11 \%$. This projection contains underlying complexity in that "IT specialist" isn't a single job type: it is a broad category. The U.S. Bureau of Labor Statistics (BLS) uses slightly different nomenclature, grouping these jobs into the "Computer and Information Technology" category, in which there are 10 sub-categories. The complexity arises when one attempts to elicit specific job titles from those sub-categories (U.S. Bureau, 2020).

What the BLS calls a Computer Programmer or Software Developer can manifest in job postings as "Full Stack Software Engineer" or "Quality Assurance Engineer". This is different from a decade or longer ago when the simple labels used by the BLS were the prevalent job ads one would find. This, however, it not merely a difference in nomenclature, it is a difference in the expectations of industry. IT-related jobs have been migrating from individual silos into more collaborative structures. Whereas a prospective candidate used to find jobs as software developers, where they would be required to have specific skills relating only to software development, a job as a Full Stack Software Engineer now requires skills that span multiple categories. The BLS categorized Computer Programmers, Database Administrators, Software Developers, and Web Developers as four separate jobs but the Full Stack Software Engineer must have all of those skills to be successful. This is the case in most areas of IT; siloed knowledge is no longer desired and broad, collaborative, and integrated knowledge is the norm. There is a growing gap between employer expectations and university curriculum, leading to skill mismatch (Kalra et al., 2020). 


\section{Issues in Information Systems}

Volume 22, Issue 2, pp. 168-176, 2021

Furthering this discussion, Dawson \& Thomson (2018) examined the need for skills that go beyond the technical realm as it pertains to the cyber security workforce (though this can be generalized to the entirety of IT). They found that skills for successful cyber worked are not only technical, but also fall into the categories of domain-specific knowledge and social intelligence. Key traits, such as being a systemic thinker, being a team player, having both technical and social skills, being loyal to the organization, having strong communication skills, and being a continual learner are all mandatory in order to be successful. Though others, such as Huang et al (2009), have examined the skills necessary for IT professionals to be successful the demand shift in the industry has introduced skill-areas that did not exist previously.

Also changing in the IT industry are the entry-level education requirements. Robin (2011) found that $70 \%$ of employers specifically require at least a Bachelor's degree for IT-related jobs. This is corroborated by the BLS, which lists a Bachelor's degree or higher as the entry-level education requirement for eight of the 10 categories of IT jobs. Recent trends in IT are making attempts to alter the education requirements to be more focused on certifications and experience than college degrees (DevMountain, 2021; Dietrich, 2018; Indeed, 2020), the reality is, as explained above, that companies are interested in the well-rounded set of skills provided by a college education, not just technical skills. With all of these complexities and discrepancies, it can be difficult for the average IT student to make sense of not only what skills companies require but also what skills they currently have and with which category those skills align.

IT students are exposed to multiple domains of information technology during their bachelors' program in universities. These students acquire a lot of knowledge about IT functionalities and develop a plethora of skillset and competencies to join the workforce upon graduation. Given the dynamic, ever-changing nature of the IT world, our students' competencies must be adequately scaled to reflect market realities. There is a global need for IT professionals and the need is perpetually increasing. Academic institutions need to understand, incorporate, and train IT's future workforce to align with the industry's future needs (Slyke, Clary, Ellis and Maasberg, 2019). The student body has its conceptions about the importance of different skills offered to them. These student perceptions directly lead to the kind of attention and hard work our students put into courses, which they believe to be more critical and in demand for the workforce. This paper aims to understand these student perceptions of the relative importance and preparedness of broader IT domains to succeed in future employment. The research questions addressed in this study are the following:

RQ1: What levels of experience in the Cyber Security domain do students in IT-related majors claim?

RQ2: What levels of experience in the Infrastructure \& Operations domain do students in IT-related majors claim?

RQ3: What levels of experience in the Software Development domain do students in IT-related majors claim?

RQ4: What levels of experience in the New \& Emerging Technologies domain do students in IT-related majors claim?

RQ5: To what degree do students have experience in non-primary domains?

The introduction section above is followed by a critical review of the relevant literature in the field. The methodology is explained and results are presented. The discussion section draws the implications of our results followed by the conclusion of the study. 


\section{Methods and results}

An online survey was developed to ascertain university students' self-assessment of their level of experience in 4 domains of the IT arena. The survey was administered across two university IT departments. Data was collected from 173 students, of which 125 completed the survey and provided useful data. We asked students their level of mastery as a proxy for their perception based on the importance of the areas where they have focused their efforts. Students were asked to identify one of the 4 areas as their primary area of experience. As can be seen in Table 1, over 61\% reported Cyber Security as their primary area with approximately equal distribution for the other three domains. Almost $80 \%$ of the students reported considering Cyber Security in their future career plans.

Table 1: Student's Primary Area of Study

\begin{tabular}{|l|l|l|}
\hline Area of Study & Frequency & Percent \\
\hline Cyber Security & 77 & $61.6 \%$ \\
\hline Infrastructure and Operations & 15 & $12.0 \%$ \\
\hline Development & 17 & $13.6 \%$ \\
\hline New and Emerging Technologies & 16 & $12.8 \%$ \\
\hline Totals & 125 & $100 \%$ \\
\hline
\end{tabular}

As can be expected, $60 \%$ of the subjects had not completed a bachelor's degree while $35.3 \%$ had earned a bachelor's degree and 3.5\% had earned a master's degree. Similarly, 72\% reported their age as 18-23 and $19.1 \%$ as $24-29$. All subjects reported being less than 50 years old. Likewise, $85.6 \%$ reported having less than 1 years' experience working in the field and 12 percent reporting 1-5 years' experience. Three subjects reported having more experience with 1 reporting more than 15 years' experience.

\section{Results}

RQ1. What levels of experience in the Cyber Security domain do students in IT-related majors claim?

The overall results for the Cyber Security domain are shown in Table 2. Mean values in all domains were at the 'Basic' level with 'Communications and Network Security' having the highest mean at 2.44. Three domains fell below 2 on the scale but were still considered at the basic level: 'Asset Security', 'Software Development Security', and 'Security Architecture and Engineering.' This domain had the lowest range in the means (0.63) and the 2nd highest overall mean (2.10).

Table 2: Self-Reported level of Security Knowledge

\begin{tabular}{|l|l|l|l|l|l|l|}
\cline { 2 - 7 } \multicolumn{1}{c|}{} & \multicolumn{7}{c|}{ Level of Experience \% } & \multicolumn{1}{c|}{} \\
\hline Sub-Domains & None & Basic & Some & Substantial & Highest & Mean \\
\hline Communications and Network Security & 10.4 & 48.8 & 27.2 & 13.6 & 0 & 2.44 \\
\hline Security and risk management & 8.9 & 52.8 & 30.1 & 8.1 & 0 & 2.37 \\
\hline Security Operations & 22.4 & 50.4 & 16 & 10.4 & 0.8 & 2.17 \\
\hline Security Assessment and Testing & 26.4 & 43.2 & 23.2 & 5.6 & 1.6 & 2.13 \\
\hline Identity and Access Management & 30.6 & 42.7 & 20.2 & 5.6 & 0.8 & 2.03 \\
\hline Asset Security & 27.2 & 54.4 & 12 & 6.4 & 0 & 1.98 \\
\hline Software Development Security & 34.4 & 45.6 & 16.8 & 3.2 & 0 & 1.89 \\
\hline Security Architecture and Engineering & 40.8 & 39.2 & 18.4 & 1.6 & 0 & 1.81 \\
\hline
\end{tabular}

RQ2: What levels of experience in the Infrastructure \& Operations domain do students in IT-related majors claim? 


\section{Issues in Information Systems}

Volume 22, Issue 2, pp. 168-176, 2021

Shown in Table 3, the students' highest mean score (3.01) was 'Application Installing, Configuration and Deployment' joining 4 other skills in the 'Some Experience' range. All of the rest were in the 'Basic' range. While 'SLA: SL Objective and SLI' (mean $=1.54)$ was technically still in the 'Basic Experience' range, almost $65 \%$ of the subjects rated their own experience as 'none'. In fact, it was the only skill in this area with the highest percentage in the 'none' range. This domain had the highest overall mean ratings for any of the skills on the survey and had the 2 nd highest range (1.04) and the highest overall mean (2.30).

Table 3: Self-Reported level of Infrastructure and Operations Knowledge

\begin{tabular}{|c|c|c|c|c|c|c|}
\hline & \multicolumn{5}{|c|}{ Level of Experience \% } & \\
\hline Domains & None & Basic & Some & Substantial & Highest & Mean \\
\hline App Installing, Config, and Deployment & 8.8 & 26.4 & 30.4 & 24 & 10.4 & 3.01 \\
\hline Operating Systems & 6.4 & 27.2 & 41.6 & 21.6 & 3.2 & 2.88 \\
\hline Networking & 5.6 & 34.4 & 42.4 & 17.6 & 0 & 2.72 \\
\hline Desktop Support & 14.4 & 31.2 & 31.2 & 14.4 & 8.6 & 2.72 \\
\hline Storage & 11.2 & 36 & 37.6 & 13.6 & 1.6 & 2.56 \\
\hline Monitoring, Alerting, Notification & 19.2 & 40 & 28 & 10.4 & 2.4 & 2.37 \\
\hline Server Management & 24 & 40 & 26.6 & 6.4 & 0.8 & 2.2 \\
\hline Incident Management & 21.2 & 44 & 12.8 & 9.6 & 2.4 & 2.08 \\
\hline Production Environment Support & 36 & 39.2 & 16 & 5.6 & 3.2 & 2.01 \\
\hline Automation - Scripting & 40 & 31.2 & 21.6 & 4.8 & 2.4 & 1.98 \\
\hline Testing Environment Support & 35.2 & 42.4 & 15.2 & 4.8 & 2.4 & 1.97 \\
\hline Cloud Administration and Support & 38.4 & 39.2 & 16 & 6.4 & 0 & 1.9 \\
\hline SLA: SL Objective and SLI & 64.8 & 21.6 & 10.4 & 0.8 & 2.4 & 1.54 \\
\hline
\end{tabular}

RQ3: What levels of experience in the Software Development domain do students in IT-related majors claim?

All of the skills in this domain, listed in Table 4, were rated in the 'Basic' level of experience with 'Programming Logic' and 'Testing and Debugging' tied for the highest mean at 2.51 and 'Abstraction' $($ mean $=1.6)$ and 'Container Application' (mean $=1.59$ ) having the lowest mean ratings. This domain had the 2 nd lowest range (0.92) in the means and the 2 nd lowest overall mean (2.0).

Table 4: Self-Reported level of New and Emerging Technologies Knowledge

\begin{tabular}{|c|c|c|c|c|c|c|}
\hline & \multicolumn{5}{|c|}{ Level of Experience \% } & \multirow[b]{2}{*}{ Mean } \\
\hline Domains & None & Basic & Some & Substantial & Highest & \\
\hline Programming Logic & 19.2 & 33.6 & 28 & 15.2 & 4 & 2.51 \\
\hline Testing and Debugging & 16 & 36.8 & 29.6 & 15.2 & 2.4 & 2.51 \\
\hline DB Admin, Management, and Dev & 17.6 & 45.6 & 28.8 & 7.2 & 0.8 & 2.28 \\
\hline User Interface Design/HCI & 36.8 & 36 & 21.6 & 4.8 & 0.8 & 1.97 \\
\hline Data Modeling & 38.4 & 37.6 & 16.4 & 5.6 & 0 & 1.91 \\
\hline $\begin{array}{l}\text { Version Control/Deployment/ } \\
\text { Config/Env }\end{array}$ & 44 & 35.2 & 12.8 & 4.8 & 3.2 & 1.88 \\
\hline Event Handling/Interrupts & 45.6 & 34.4 & 16 & 3.2 & 0.8 & 1.79 \\
\hline Abstraction & 59.2 & 24.8 & 12.8 & 3.2 & 0 & 1.6 \\
\hline Container Application & 60 & 27.2 & 6.4 & 6.4 & 0 & 1.59 \\
\hline
\end{tabular}

$R Q 4:$ What levels of experience in the New \& Emerging Technologies domain do students in IT-related majors claim? 


\section{Issues in Information Systems}

Volume 22, Issue 2, pp. 168-176, 2021

One of the areas in this domain, shown in Table 5, 'Internet of Things', ranked at the 'Some' experience level with two ranked at the 'none' level: 'Robotic Process Automation' (mean = 1.43) and 'Quantum Computing' (mean =1.41). The rest were ranked at the 'Basic' level of experience. The range for this domain was 1.18 , the highest of any of the domains, and had the lowest overall mean (1.85).

Table 5: New and Emerging Technologies

\begin{tabular}{|l|l|l|l|l|l|l|}
\multicolumn{1}{c|}{} & \multicolumn{7}{c|}{ Level of Experience \% } & \multicolumn{1}{c|}{} \\
\hline Domains & None & Basic & Some & Substantial & Highest & Mean \\
\hline Internet of Things & 12 & 36 & 34.4 & 16 & 1.6 & 2.59 \\
\hline Virtual/Augmented Reality & 23.2 & 37.6 & 30.4 & 8 & 0.8 & 2.26 \\
\hline Crypto Currency & 21.6 & 43.2 & 24.8 & 9.6 & 0.8 & 2.25 \\
\hline Cloud Computing and Cloud Tech & 25.6 & 47.2 & 20.8 & 5.6 & 0.8 & 2.09 \\
\hline Data Science & 33.9 & 41.9 & 16.1 & 7.3 & 0.8 & 1.99 \\
\hline Machine Learning and Automation & 45.2 & 39.5 & 12.9 & 2.4 & 0 & 1.73 \\
\hline Enterprise/Intelligent Automation & 53.6 & 36 & 838 & 0.8 & 0.8 & 1.59 \\
\hline Edge Computing & 63.2 & 19.2 & 15.2 & 2.4 & 0 & 1.57 \\
\hline Block Chain & 60.8 & 27.2 & 9.6 & 2.4 & 0 & 1.54 \\
\hline Robotic Process Automation & 64.8 & 27.2 & 0.8 & 0 & 0 & 1.43 \\
\hline Quantum Computing & 67.2 & 25.6 & 6.4 & 0.8 & 0 & 1.41 \\
\hline
\end{tabular}

RQ5: To what degree do students have experience in non-primary domains?

Table 6 shows the means for each of the 4 domains grouped by the self-reported primary area for each subject. As can be seen in the table, the means in the matching domain to the subjects reported primary domain (italicized) do not reflect an interaction, except with the Overall mean. In fact, the students reporting their primary domain as 'New and Emerging Technology' actually had their lowest reported experience rating in that same domain.

It still should be noted that the means in all areas, both primary and non-primary, were all within the same 'basic' level of experience.

Table 6: Primary Domain vs Means in Each Domain

\begin{tabular}{|l|c|c|c|c|c|}
\hline \multirow{2}{*}{ Primary Area } & \multirow{2}{*}{$\mathbf{N}$} & \multicolumn{5}{c|}{ Means in the Domains } \\
\cline { 3 - 7 } & & CS & I/O & Dev & New \\
\hline Cyber Security & 77 & 2.22 & 2.24 & 1.94 & 1.91 \\
\hline Infrastructure and Operations & 15 & 2.14 & 2.69 & 2.31 & 2.01 \\
\hline Development & 17 & 1.92 & 2.24 & 2.17 & 1.69 \\
\hline New and Emerging Technologies & 16 & 1.71 & 1.89 & 1.81 & 1.61 \\
\hline Overall & 125 & 2.10 & 2.30 & 2.00 & 1.85 \\
\hline
\end{tabular}

In addition to answering the research questions, the researchers noted some additional interesting findings. Tables 7, 8 , and 9 (when put together) show a combined table of means across all domains. Table 7 shows the 8 areas that are ranked at the 'Some' experience level. While the majority of these are from the Infrastructure and Operations domain, both the New Technologies and Development domains were included. No sub-domains from the Security domain were ranked at this level. 
Table 7: Overall - Sub-Domains at the 'Some Experience level'

\begin{tabular}{|c|c|c|c|c|c|c|c|}
\hline & \multicolumn{5}{|c|}{ Level of Experience \% } & \multirow[b]{2}{*}{ Mean } \\
\hline & & None & Basic & Some & Substantial & Highest & \\
\hline $\begin{array}{l}\text { App Installing, Config, and } \\
\text { Deployment }\end{array}$ & $\operatorname{Inf}$ & 8.8 & 26.4 & 30.4 & 24 & 10.4 & 3.01 \\
\hline Operating Systems & Inf & 6.4 & 27.2 & 41.6 & 21.6 & 3.2 & 2.88 \\
\hline Networking & Inf & 5.6 & 34.4 & 42.4 & 17.6 & 0 & 2.72 \\
\hline Desktop Support & Inf & 14.4 & 31.2 & 31.2 & 14.4 & 8.6 & 2.72 \\
\hline Internet of Things & New & 12 & 36 & 34.4 & 16 & 1.6 & 2.59 \\
\hline Storage & Inf & 11.2 & 36 & 37.6 & 13.6 & 1.6 & 2.56 \\
\hline Programming Logic & Dev & 19.2 & 33.6 & 28 & 15.2 & 4 & 2.51 \\
\hline Testing and Debugging & Dev & 16 & 36.8 & 29.6 & 15.2 & 2.4 & 2.51 \\
\hline
\end{tabular}

Table 8 shows the 32 areas that are ranked at the 'Basic' Experience level. All four domains were present in this, the largest grouping of the sub-domains.

Table 8: Overall - Sub-Domains at the 'Basic Experience level'

\begin{tabular}{|c|c|c|c|c|c|c|c|}
\hline & \multicolumn{5}{|c|}{ Level of Experience \% } & \multirow[b]{2}{*}{ Mean } \\
\hline & & None & Basic & Some & Substantial & Highest & \\
\hline $\begin{array}{l}\text { Communications and Network } \\
\text { Security }\end{array}$ & Sec & 10.4 & 48.8 & 27.2 & 13.6 & 0 & 2.44 \\
\hline Security and Risk Management & $\mathrm{Sec}$ & 8.9 & 52.8 & 30.1 & 8.1 & 0 & 2.37 \\
\hline Monitoring, Alerting, Notification & $\mathrm{Sec}$ & 19.2 & 40 & 28 & 10.4 & 2.4 & 2.37 \\
\hline DB Admin, Management, and Dev & Dev & 17.6 & 45.6 & 28.8 & 7.2 & 0.8 & 2.28 \\
\hline $\begin{array}{l}\text { Virtual Reality and Augmented } \\
\text { Reality }\end{array}$ & New & 23.2 & 37.6 & 30.4 & 8 & 0.8 & 2.26 \\
\hline Crypto Currency & New & 21.6 & 43.2 & 24.8 & 9.6 & 0.8 & 2.25 \\
\hline Server Management & Inf & 24 & 40 & 26.6 & 6.4 & 0.8 & 2.2 \\
\hline Security Operations & $\mathrm{Sec}$ & 22.4 & 50.4 & 16 & 10.4 & 0.8 & 2.17 \\
\hline Security Assessment and Testing & $\mathrm{Sec}$ & 26.4 & 43.2 & 23.2 & 5.6 & 1.6 & 2.13 \\
\hline Cloud Computing and Cloud Tech & Inf & 25.6 & 47.2 & 20.8 & 5.6 & 0.8 & 2.09 \\
\hline Incident Management & Inf & 21.2 & 44 & 12.8 & 9.6 & 2.4 & 2.08 \\
\hline Identity and Access Management & Sec & 30.6 & 42.7 & 20.2 & 5.6 & 0.8 & 2.03 \\
\hline Production Environment Support & Inf & 36 & 39.2 & 16 & 5.6 & 3.2 & 2.01 \\
\hline Data Science & New & 33.9 & 41.9 & 16.1 & 7.3 & 0.8 & 1.99 \\
\hline Asset Security & $\mathrm{Sec}$ & 27.2 & 54.4 & 12 & 6.4 & 0 & 1.98 \\
\hline Automation - Scripting & Inf & 40 & 31.2 & 21.6 & 4.8 & 2.4 & 1.98 \\
\hline Testing Environment Support & Inf & 35.2 & 42.4 & 15.2 & 4.8 & 2.4 & 1.97 \\
\hline User Interface Design/HCI & Dev & 36.8 & 36 & 21.6 & 4.8 & 0.8 & 1.97 \\
\hline Data Modeling & Dev & 38.4 & 37.6 & 16.4 & 5.6 & 0 & 1.91 \\
\hline Cloud Administration and Support & Inf & 38.4 & 39.2 & 16 & 6.4 & 0 & 1.9 \\
\hline Software Development Security & Sec & 34.4 & 45.6 & 16.8 & 3.2 & 0 & 1.89 \\
\hline $\begin{array}{l}\text { Version Control/Deployment/ } \\
\text { Config/Env }\end{array}$ & Dev & 44 & 35.2 & 12.8 & 4.8 & 3.2 & 1.88 \\
\hline $\begin{array}{l}\text { Security Architecture and } \\
\text { Engineering }\end{array}$ & Sec & 40.8 & 39.2 & 18.4 & 1.6 & 0 & 1.81 \\
\hline Event handling/Interrupts & Dev & 45.6 & 34.4 & 16 & 3.2 & 0.8 & 1.79 \\
\hline Machine Learning and Automation & New & 45.2 & 39.5 & 12.9 & 2.4 & 0 & 1.73 \\
\hline Abstraction & Dev & 59.2 & 24.8 & 12.8 & 3.2 & 0 & 1.6 \\
\hline Container Application & Dev & 60 & 27.2 & 6.4 & 6.4 & 0 & 1.59 \\
\hline Enterprise/Intelligent Automation & New & 53.6 & 36 & 838 & 0.8 & 0.8 & 1.59 \\
\hline
\end{tabular}




\section{Issues in Information Systems}

Volume 22, Issue 2, pp. 168-176, 2021

\begin{tabular}{|l|l|l|l|l|l|l|l|}
\hline Edge Computing & New & 63.2 & 19.2 & 15.2 & 2.4 & 0 & 1.57 \\
\hline SLA: SL Objective and SLI & Inf & 64.8 & 21.6 & 10.4 & 0.8 & 2.4 & 1.54 \\
\hline Block Chain & New & 60.8 & 27.2 & 9.6 & 2.4 & 0 & 1.54 \\
\hline
\end{tabular}

Table 9 shows the two areas that were self-ranked at the 'None' level: 'Robotic Process Automation' and 'Quantum Computing'. Both of these were in the New and Emerging Technologies domain, which not surprisingly dominated the lower end of the table given their typical lack of coverage in undergraduate degree programs.

\begin{tabular}{|c|c|c|c|c|c|c|c|}
\hline & & \multicolumn{5}{|c|}{ Level of Experience \% } & \multirow[b]{2}{*}{ Mean } \\
\hline & & None & Basic & Some & Substantial & Highest & \\
\hline Robotic Process Automation & New & 64.8 & 27.2 & 0.8 & 0 & 0 & 1.43 \\
\hline Quantum Computing & New & 67.2 & 25.6 & 6.4 & 0.8 & 0 & 1.41 \\
\hline
\end{tabular}

\section{Discussion}

This study has implications for practice and research. IT skills preferred by employers allow academic institutions to adapt and refine program offerings to their students. It gives clarity on "why" these institutions are offering specific skills. However, to better understand "what" is being offered and "how" it is delivered requires a sound understanding of student perceptions about the relative importance of IT skills and knowledge. Educators are positioned to gauge student interest better and provide helpful guidance when they understand the students' perceptions about the importance of various domains in IT education. Our results provide a broad and multi-layered view of students' IT skills and adapt our offerings to the given context. Computing Curricula (2020) identifies developing competencies in students by focusing on knowledge in the field, skills or know-how, and dispositions (the intellectual, social, and moral tendencies) of students (CC2020, 2021). The report presents a competency framework that acknowledges the role of students questioning "why" they need to learn specific skills. The report urges to refresh the paradigm of teaching and to educate, moving from knowledge or outcomes to proficiencies and engaging graduates, to exploit the benefits of workplace competencies. This paper significantly contributes to research in understanding students' perception of the relative importance of IT skills. It is important to educate students on what skills and competencies are valued in industry. The preferable "dispositions" of students allow them to succeed in employment of their choices and it is of great practical value to nurture it.

\section{Conclusion}

This study of the recent IT graduates or the students who are about to graduate shows that not many students admit substantial level of expertise in any of the four areas of IT, and very few students admit the highest level of expertise in those areas. The participants claim mainly basic level of expertise in Cyber Security; Communication/Network Security and Risk Management being slightly above the basic level. In half of the domains of Infrastructure and Operations, the graduates claim a substantially higher than basic level of expertise, with a few fields being very close to substantial expertise. In most areas of expertise in Software Development the respondents admitted that their skills were below the basic level; however, the areas of Programming Logic and Testing/Debugging scored above the basic level. Finally, about a third of the areas in Emerging Technologies ranked slightly above the basic level, while the remaining areas were below the basic level. The only one area in this category where the students' expertise was close to high was the Internet of Things. Surprisingly, the students majoring in a certain area tend to not admit the highest level of expertise in that area. For example, the respondents whose area of study was Cyber Security admitted 


\section{Issues in Information Systems}

Volume 22, Issue 2, pp. 168-176, 2021

the highest level of expertise in Infrastructure and Operations. There results of the paper allow us to outline the areas of IT in which the graduating students' expertise does or does not meet the workplace requirements.

\section{References}

Aasheim, C.L., Li, L. and Williams, S. (2006). Knowledge and skill requirements for entry-level information technology workers: a comparison of industry and academia. Journal of Information Systems Education, 20(3), pp. 349-356.

Abraham, T., Beath, C., Bullen, C., Gallagher, K., Goles, T., Kaiser, K., and Simon, J. (2006). IT Workforce Trends: Implications for IS Programs. Communications of the Association for Information Systems, 17, pp. 1147-1170.

CC2020, (2020). Computing Curricula 2020 Paradigms for Global Computing Education, Retrieved on 04/20/2021 https://www.acm.org/binaries/content/assets/education/curricularecommendations/cc2020.pdf

Dampier, D. (2015). Building a successful cyber-security program. Distributed Analytics and Security Institute, Mississippi State University. Retrieved on April 10, 2019 at http://www.dasi.msstate.edu/publications/docs/2015/06/13502Cyber_Security_Workshop_paper_ __Final.pdf

Dawson, J. \& Thomson, R. (2018). The future cybersecurity workforce: Going beyond technical skills for successful cyber performance. Frontiers in Psychology, 9, 12.

DevMountain. (2021, March 18). Certifiable? Finding programmer jobs without a degree. https://blog.devmountain.com/certifiable-finding-programmer-jobs-without-a-degree/

Dietrich, E. (2018, April 9). How to get a programming job without a degree. DaedTech. https://daedtech.com/programming-job-without-degree/

Haney, J., M., \& Lutters, W.G., (2016). Skills and characteristics of successful cybersecurity advocates. Retrieved from https://www.usenix.org/system/files/conference/soups2017/wsiw2017-haney.pdf

Hollister, J.M., Spears, L.I., Mardis, M.A., Lee, J., McClure, C.R., and Liebman, E. (2017). Employers' perspectives on new information technology technicians' employability in North Florida. Education and Training; London, 59(9), pp. 929-945.

Huang, H., Kvasny, L., Joshi, KD, Trauth, E., \& Mahar, J. (2009, May). Synthesizing IT job skills identified in academic studies, practitioner publications and job ads [Conference paper]. Proceedings of the special interest group on management information system's 47th annual conference on Computer personnel research, SIGMIS-CPR, Limerick, Ireland, 121-128.

Indeed Career Guide. (2020, December 22). 10 high-paying IT jobs you can get without a degree. Indeed. https://www.indeed.com/career-advice/finding-a-job/it-jobs-without-degree

Kalra, S., Thevathan, C., and Hamilton, M. (2020). Developing Industry-Relevant Higher Order Thinking Skills in Computing Students, In Proceedings of the 2020 ACM Conference on Innovation and 


\section{Issues in Information Systems}

Volume 22, Issue 2, pp. 168-176, 2021

Technology in Computer Science Education (ITiCSE '20), June 15-19, 2020, Trondheim, Norway. ACM, New York, NY, USA, 6 pages. https://doi.org/10. 1145/3341525.3387381

Kapoor, A. and Gardner-McCune, C. (2018). Understanding Professional Identities and Goals of Computer Science Undergraduate Students, In proceedings of SIGCSE'18, February 21-24, 2018, Baltimore, MD, USA

Koh, S., Lee, S., Yen, D.C. and Havelka, D. (2004). The relationship between information technology professionals' skill requirements and career stage in the e-commerce era: an empirical study. Journal of Global Information Management; Hershey, 12(1), pp. 68-82.

Madden, J. (2021). Top IT skills in demand in 2021. CompTIA, retrieved on 4/10/2021 from https://www.comptia.org/blog/top-it-skills-in-demand

McKenzie, S. and Coldwell-Nielson, J. (2018). Understanding the career development and employability of information technology students. Journal of Applied Research in Business Education; Bingley, 10(4), pp. 456-468.

Pham, A. and Dao, H. (2020). The Importance of Soft Skills for University Students in the $21^{\text {st }}$ Century, In proceedings of ICAAI 2020, October 09-11, 2020, London, United Kingdom, Association for Computing Machinery

Purdue Global (2018). Bachelor of Science in Cybersecurity. Retrieved on April 15, 2019 at https://www.purdueglobal.edu/degree-programs/information-technology/bachelorscybersecurity.pdf

Robin, G. J. (2011, May). Do companies look for education, certifications, or experience: a quantitative analysis [Conference paper]. Proceedings of the 49 th SIGMIS annual conference on computer personnel research, SIGMIS-CPR, San Antonio, TX, USA, 1-5.

Song, X., Huang, X., and Huang, K. (2019). Research on the Effect of Skill Mismatch on Skill Development and Job Satisfaction among Graduates, In proceedings of ICEME 2019, July 15-17, 2019, Beijing, Association for Computing Machinery

Taylor-Smith, E., Berg, T., Smith, S., Meharg, D., Fabian, K. and Varey, A. (2019). Bridging the Digital Skills Gap, In Proceedings of ITiCSE '19, July 15-17, 2019, Aberdeen, Scotland UK, Association for Computing Machinery

U.S. Bureau of Labor Statistics. (2020, September 1). Computer and Information Technology Occupations. https://www.bls.gov/ooh/computer-and-information-technology/home.htm

Van Slyke, C., Clary, G., Ellis, S. and Maasberg, M. (2019). Employer Preferences for Cybersecurity Skills among Information Systems Graduates, In proceedings of the SIGMIS-CPR '19, June 20 22, 2019, Nashville, TN 